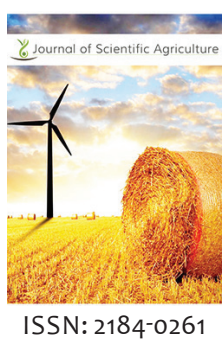

Received: April 05, 2020 Accepted: May 03, 2020 Published: May 06, 2020

*corresponding Author: Alvin D. Palanog

Email:a_palanog@yahoo.com

\title{
Rice breeding strategies in the Philippines
}

\section{Alvin D. Palanog ${ }^{1 *}$, Cielo Luz Mondejar', Gerald E. Bello', Mark Ian Calayugan², May O. Palanog', Xavier Greg Caguiat', Marilyn Ferrer ${ }^{3}$, Leo T. Sta. Ines ${ }^{1}$}

\author{
'Philippine Rice Research Institute, Negros Branch, Murcia, Negros Occidental, Philippines, ${ }^{2}$ University of the \\ Philippine, Los Baňos, Laguna, Philippines, ${ }^{3}$ Philippine Rice Research Institute, Central Experiment Station, \\ Nueva Ecija, Philippines
}

\begin{abstract}
Rice is a major staple in the Philippines. The major goal of the rice sector in the country is to increase rice productivity to meet the ever growing demand for rice. Breeding is one of the potential solutions to achieve rice self-sufficiency. Rice variety development is led by research institutions such as PhilRice, IRRI, UPLB, and private companies and each adapts various breeding strategies. Rice variety normally takes 10-12 years of a journey from breeding to release and more than 300 varieties have been developed and released that were suited for various rice ecosystems. Sufficient varieties were available for production and this led to continuous in rice production for the past decade. However, yield increment has plateaued. To meet the increasing demand for rice, achieve self-sufficiency, and break the yield barrier (plateau) and achieve a leap in yield potential, breeding institutions particularly PhilRice should embrace new advances and technologies in rice breeding. The introduction of the concept of transforming breeding into a "factory line" type encouraging rapid generation advance, earlier multi-location trials, and increasing selection pressure, and employing genomic selection (GS) in handling a large quantity of materials/populations can improve breeding efficiency and outputs significantly.
\end{abstract}

KEYWORDS: Breeding strategies, National Seed Industry Council (NSIC), rice, variety development

\section{INTRODUCTION}

Rice is the major staple food of the Filipino people. The demand for rice continues to increase as population constantly grows at a rate of $1.7 \%$ every year. Increasing productivity is one of the top priorities in rice breeding to address the consumption demand of the country. Generally, breeding in the country is directed to achieve desirable traits such as high grain yield, resistance to biotic and abiotic stresses, wide adaptability, and grain qualities acceptable to consumers. Lead breeding institutions like the International Rice Research Insitute (IRRI), Philippine Rice Research Institute (PhilRice), University of the Philippines (UPLB) have developed varieties intended for various rice ecosystems (irrigated lowland, rainfed, upland, saline-prone, cool-elevated) and are adaptable for various locations (regional, national). The development and dissemination of new and improved rice varieties provide an opportunity for the rice farmers to increase productivity and profitability, and improve food security of rice farming households [1].

Rice production in the country continues to face challenges and constraints that hamper its growth. Among the major constraints are: adverse climatic conditions such as drought, flooding, and salt-water intrusion mainly brought by climate change, pest infestations of both new and emerging pests, abiotic stresses such as nutrient deficiencies and toxicities, and plateauing of yield growth. Social aspect such as continuous decline of production areas due to land conversion and increasing demand due population growth also create additional pressure on production. To address these challenges, appropriate breeding strategies along with integrated management technologies incorporating modern biotechnology tools are being employed to developed promising lines suited for target ecosystems. Each breeding institution has unique breeding strategies to achieve their breeding objectives. One of the essential components of successful breeding, is the presence of large degree of variability in the germplasms during the pre-breeding phase. Breeding lines, germplasm materials, wild relatives, and materials from other countries have intensively used as source of important genes for rice improvement in the country. Multi-locations and multidisciplinary evaluation of elite breeding lines that satisfy the diversity of various agro-ecological zones measures the adaptability potential of the lines has deemed important 
stage in the breeding programs recently. Molecular assisted selection (MAS) coupled with high-throughput genotyping and phenotyping are becoming integral tool in fast-tracking breeding cycles and increasing precision in targeting genes of important traits.

This paper aims to review the various rice breeding strategies design by several leading agencies which include: IRRI, PhilRice, UPLB, and some non-government organizations (NGO); variety development process in the country from evaluation to release, and future breeding strategies and progress that address current challenges in rice production in the Philippines.

\section{Variety Development in the Philippines}

Breeding institutions such as IRRI, PhilRice, UPLB, and some private companies are the major players in developing rice varieties in the Philippines [2]. Promising lines developed by each institution are submitted and evaluated in the National Cooperative Testing (NCT) spearheaded by the Rice Varietal Improvement Group (RVIG) - composed of various research institutions and agencies (Figure 1) responsible for testing, evaluating, and recommending promising lines to National Seed Industry Council (NSIC) for release. Promising lines are evaluated under various locations across the country for 2 years ( 2 dry seasons and 2 wet seasons). Promising lines passed the evaluation are submitted to Rice Technical Working Group (RTWG) for recommendation. Subsequently, the group submit the list of prospective varieties to National Seed Industry Council (NSIC) for release. Upon approval of release, breeding institution(s) submit breeder seeds to PhilRice for seed multiplication and production of foundation seeds (FS) is done by PhilRice and its network (Figure 2). Foundation seeds are further multiplied into certified seeds (CS) which are eventually utilized by rice farmers (Figure 2). An average of four varieties are released every year. From its first released in 1955, 387 rice varieties have been approved for released as of this moment which were recommended for various ecosystems (irrigated, rainfed, upland, saline-prone, cool-elevated), national or regional release, crop establishments (direct seeded and transplanted), seasons (dry and wet). Majority of varieties released were intended for irrigated lowland followed by rainfed ecosystem $>$ upland $>$ saline-prone and cool-elevated (Figure 3).

\section{Breeding Strategies and Programs by Institutions}

Breeding institutions design their breeding programs fitted on the need of the target users particularly farmers. Most of the breeding strategies follow the general concept in breeding which include: creating and exploiting genetic variability on the materials or germplasms used, hybridization or crossing pureline parents which may vary depending on their preferred techniques, and pedigree method as the most common selection method used. Numerous varieties had been released by the National Seed Industry Council (NSIC) formerly Philippine Seed Borad (PSB) that are intended for various target ecosystems. The varieties released are bred by breeding institutions such as IRRI, PhilRice, or UPLB (Figure 1). Below the breeding programs, targets, and strategies employed by each institutions.

\section{International Rice Research Institute (IRRI)}

IRRI is an international agricultural research and training organization that aims to improve livelihoods and nutrition,

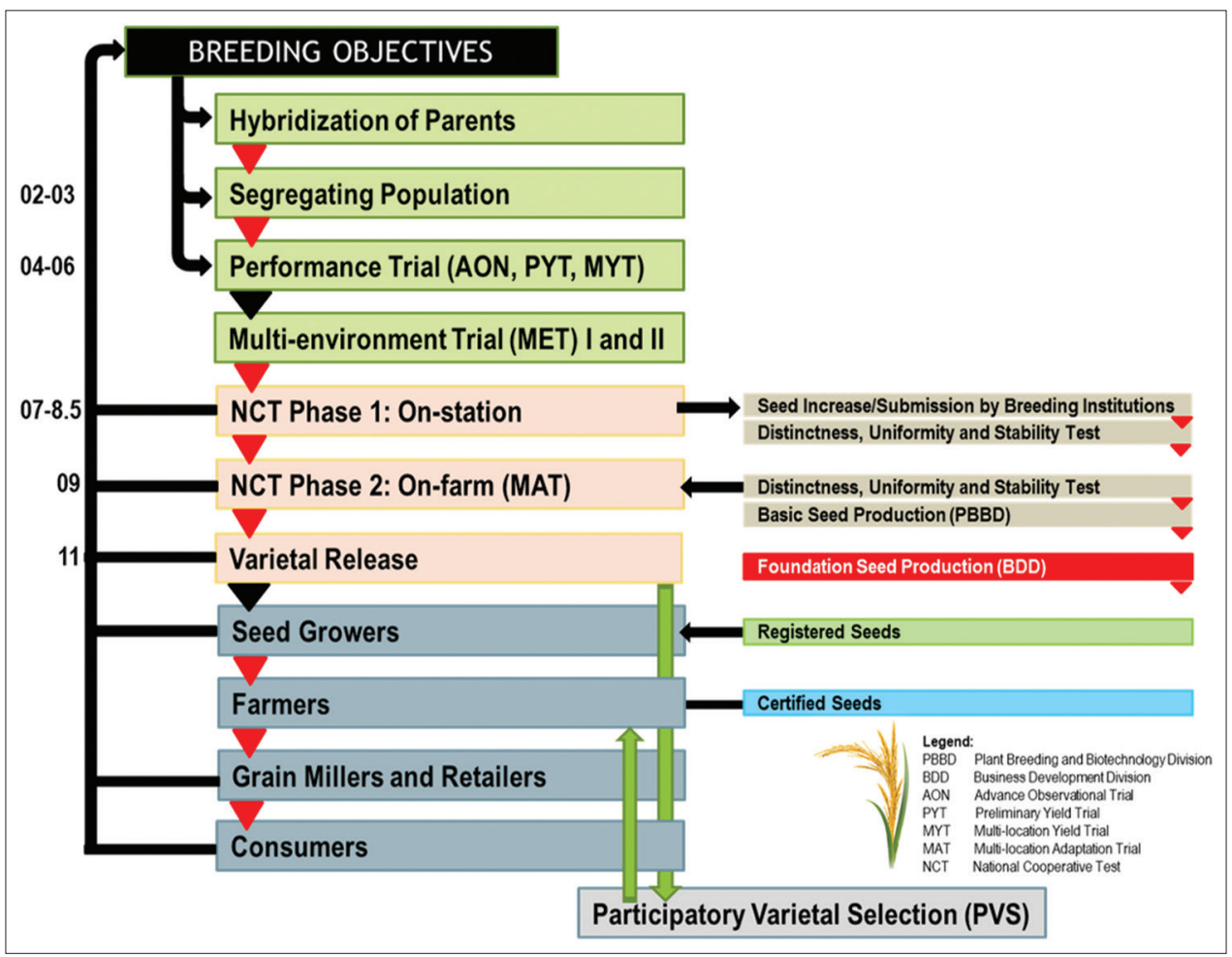

Figure 1. Rice varietal development process in the Philippines 


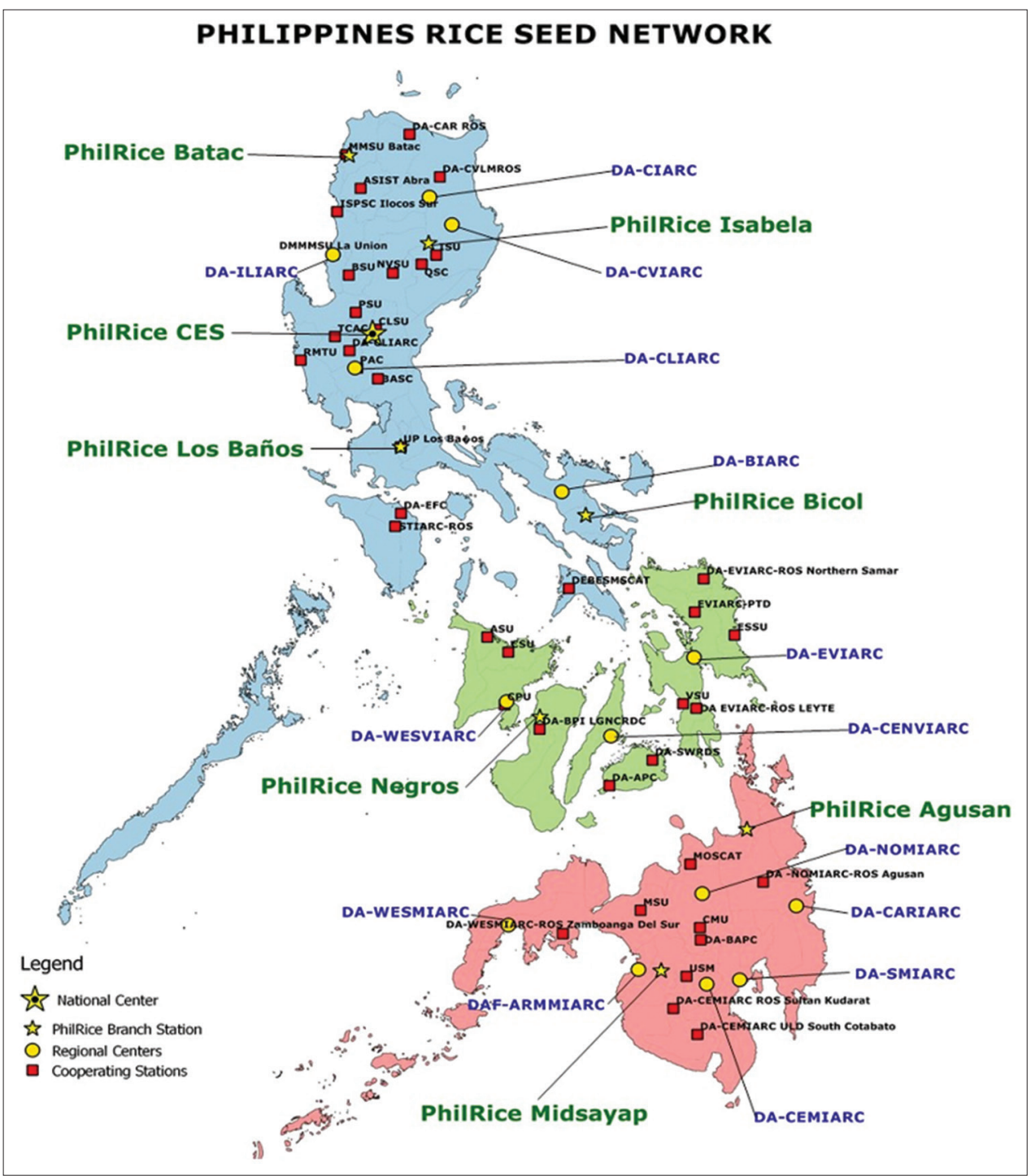

Figure 2. Rice R\&D Network in the Philippines

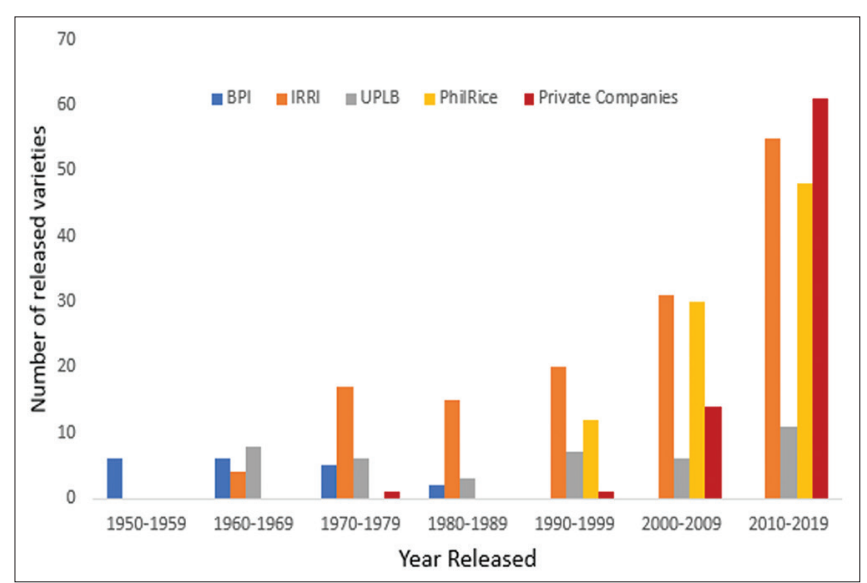

Figure 3. Number of released varieties bred by various breeding institutions from 1950 to 2019. (Source: National Seed Industry Council (NSIC)

abolishing poverty, hunger and malnutrition among those who depend on rice-based agri-food systems. The institute is known for its work in developing rice varieties that contributed to the Green Revolution in the 1960s. IR8 was the first developed variety by IRRI. This variety established the basic plant type of the high-yielding varieties (HYVs) we have today [3]. The varieties subsequently developed and released over the next two decades with improved traits on poor grain quality, lack of disease and insect resistance and late maturity [4]. In early 1980s, one of the most popular varieties grown was IR36. In addition to its disease and insect resistance, it achieved its high yield in a period of only 111 days from seed to seed, compared to 130 days of IR8 [5]. It spread rapidly and was estimated to be planted in more than 10 million ha during the 1980s. In 1985, IR64 was released in the Philippines. IR64 replaced IR36 in most growing areas and spread rapidly in new areas. IR64 represented a breakthrough in combining excellent palatability of cooked rice with the other traits found in previous IRRI HYVs. Because of its wide adaptation, it became a standard for high-quality rice and was highly desired by the rice industry [3]. And, it has been used widely as a representative indica variety in research studies. It has also been used extensively as a parent in breeding 
programs, and to develop populations for genetic analysis. IR64 was replaced by newer varieties in the early 2000s mainly due to its susceptibility to tungro disease. However, the breeders have attempted to retain the quality traits of IR64. PSB Rc82 is an example of a variety that became very popular, and IR64 is one of its grandparents. IRRI scientists still develops advanced rice varieties that yield more grain, can withstand better in pests and disease, and have superior grain quality. Its key research areas include breeding for favourable environments, quantitative genetics and host plant resistance [6]. These are to optimize rice varieties and cropping systems for intensive rice-growing areas, study rice measurable phenotypes that depend on the cumulative actions of many genes and the environment, and discover and apply the resistance of rice plants to various environmental stresses, respectively. Higher-yielding varieties are being develop by harnessing the power of quantitative genetics to systematically improve the performance of an elite breeding pool for key agronomic traits, including yield. The breeding cycles are accelerated through rapid generation advance technology. It allows scientists and researchers to test new material more quickly and recycle superior genetics in the next breeding cycle. One hundred forty-one rice varieties released in the Philippines were developed by IRRI from 1967 to 2019.

Water shortage is becoming an increasing problem in traditionally irrigated areas because of depleting groundwater resources and competing uses from other sectors. Cultivating rice under such conditions requires genotypes adapted to dry direct seeding with traits such as early vegetative vigor, are competitive with weeds, have strong root systems, and are also resistant to lodging, root pathogens, nematodes and herbicides. Genetic diversity exists for these traits, and most elite breeding lines are crossed with existing high-yielding varieties to develop improved varieties for these systems. A key strategy use in IRRI is genomic prediction to allow for the selection of superior recombinants in early generation breeding trials [7].

Hybrid rice technology aims to increase the yield potential of rice beyond the level of inbred HYVs by exploiting the phenomenon of hybrid vigour or heterosis. IRRI has been developing hybrid rice technology since 1979. The institute has continued to develop new CMS (cytoplasmic male sterility), maintainer and restorer lines in diverse cytoplasmic and nuclear backgrounds over the past years. Since 1994, public rice hybrids have been released in Philippines by IRRI. Several of these combinations were derived from IRRI-bred parental lines. Work on two-line hybrid rice breeding using TGMS (thermo-genic male sterility) system has been intensified. Two stable TGMS lines (IR 73827$23 \mathrm{~S}$ and IR 73834S) were identified for use in the tropics. These lines are stale for male sterilty during the wet and dry seasons which is an indication that their critical sterility point is lower than in earlier-developed lines. A number of experimental rice hybrids derived from these lines are in the initial evaluation trials. Marker-aided selection (MAS) is being used, with SSR marker RMll for TGMS involving tms 2 gene located on chromosome 7 to identify heterozygote plants in F2, F3 and $\mathrm{F} 4$ generations for advancing the generation of crosses made to breed TGMS lines. This approach increases breeding efficiency. MAS is also being used at IRRI to pyramid various known tms genes to improve stability of TGMS lines. In order to further enhance heterosis, elite new plant type (NPT) lines are being used as one of the parents in crosses with elite indica lines. Both CMS and TGMS systems are being used to develop female and male parents of the experimental hybrids. Some of the indical NPT crosses show hybrid sterility; this is being overcome using wide compatibility genes. More than 15 genes for this trait have been reported in literature. The neutral allele has been targeted at S-5 locus, on chromosome 6. STS marker, RG 213, was successfully used to screen WC lines among NPT restorer lines. Six putative heterotic groups in rice have also been identified (Xu et al., unpublished), which should help to breed rice hybrids with enhanced heterosis. The molecular breeding programme at IRRI is identifying heterotic gene blocks in rice for subsequent incorporation into elite parental lines to improve their combining ability. Some hybrid rices appear to perform well in aerobic rice and under inland salinity conditions [8]. The International Rice Genebank at IRRI holds the world's largest collection of rice accessions. One of its objectives is the development of its capacity to incorporate high-value traits into successive new generations of rice using new molecular breeding techniques such as gene editing. A new gene editing tool called CRISPR-Associated Protein (Cas) 9 System is used at IRRI (6). It is a revolutionary, low-cost method of precision alteration of genes that enables activity to be turned on and off reversibly. Unlike other approaches to genetic modification, the plants from CRISPR/Cas 9 gene editing rely only on genes already contained in their DNA. The technique has vast potential to rapidly develop protection for rice varieties against biotic and climate-related stresses. It may even become critical in enabling researchers to keep ahead of the evolution of rice pests and diseases. One of its goals is to utilize genetic resources and modern technologies to develop better climate resilient varieties. NSIC Rc 222 were among the top four most preferred rice varieties in the Philippines recently.

\section{University of the Philippines Los Banos (UPLB)}

UPLB is a public research university and originally established as the University of the Philippines College of Agriculture (UPCA) in March 6, 1909. The university was known for the Center of Excellence in Research in the Philippines. It played an influential role in Asian Agriculture and Biotechnology due to its pioneering efforts in plant breeding and bioengineering, particularly in the development of high-yielding and pest-resistant crops. Its Rice Program under the College of Agriculture undertakes a continuous development of adaptive rice varieties through Rice Varietal Improvement Program (RVIP). The program has conducted several rice breeding activities to breed desirable rice lines from important prewar varieties and improved the commercially available rice varieties. It has amassed a huge volume of information related to rice breeding and production such as the discovery of wild rice species, hybrid vigor, genetic and inheritance studies, and pest resistance screening. It pushes new technologies and molecular-based approaches such as marker-assisted selection to complement conventional breeding strategies in producing climate-resilient rice varieties. In 1951, the program became part of the Rice and Corn Seed Improvement Project which 
was the predecessor of the National Cooperative Testing (NCT) Project that facilitates the orderly varietal testing scheme in the country. The program has assembled 849 accessions of traditional Philippine rice varieties and 35 accessions of four wild rice species. These accessions are conserved at a short-term storage facility in UPLB. Accessions are available to public until now. In 1963, the program produced 32 commercial varieties, including the notable C4-63 or $\mathrm{C} 4$, a high- yielding irrigated lowland rice variety with excellent grain and eating quality. Other varieties developed by the UPLB include upland varieties, irrigated lowland varieties and rain-fed lowland varieties. Its PSB Rcl4 is a popular variety being milled as "Pinawa” or brown rice. Its PSB Rc98 is a widely grown variety in Northern Luzon. In 1985, the first glutinous variety released by NSIC was developed by UPLB, the NSIC Rc13 or Malagkit 1. In 1999, UPLB started to develop superior TGMS-based hybrids. These hybrids utilize TGMS lines from PhilRice and IRRI. The two hybrids developed by UPLB in collaboration with PhilRice were the NSIC Rc202H (Mestiso 19) and NSIC Rc204H (Mestiso 20). Most recently, NSIC RC272 (Tubigan 4), NSIC Rc282 (Tubigan 7) and NSIC Rc286 (Tubigan 9) were released in 2011 [9].

\section{Philippine Rice Research Institute (PhilRice)}

PhilRice is a government corporate entity under the Department of Agriculture created through Executive Order 1061 on November 5, 1985 to develop high-yielding and costreducing technologies so farmers can produce enough rice for all Filipinos. It's Plant Breeding and Biotechnology Division leads the efforts in the conservation, development, improvement and utilization of appropriate rice varieties towards sustainable, profitable and competitive farming. It has a separate division that leads efforts on conservation and management of rice genetic resources, the Genetic Resources Division that conserve improved varieties and elite breeding lines of PhilRice, rice genetic materials from other breeding and research institutes, as well as indigenous traditional Philippine cultivars. The breeding activities of PhilRice aim to achieve desired traits such as high grain yield, resistance to abiotic and biotic stresses, and good grain qualities acceptable to consumers. Restricting factors such as biotic and abiotic stresses affect rice growth and development under different environmental conditions. These factors greatly affect yield which in turn affect the ability to cater the incessant increase in rice demand. Under these complex and variable environments, breeding objectives are shifted to developing varieties, which are adapted to specific target environments: rainfed-drought, submergence, high temperature, and low temperature conditions. To address these constraints and challenges, breeding strategies including integrated management technologies, Marker-Assisted Selection (MAS), classical hybridization and biotechnology, in-vitro culture, in-vitro mutagenesis, anther culture, root plasticity development, and introgression of rice tungro virus and bacterial blight disease resistance genes are employed to generate and develop improved breeding lines for the target ecosystem (Figure 4). Breeding lines, existing varieties, and wild relatives are screened for particular traits in search for genes and donors useful in breeding.

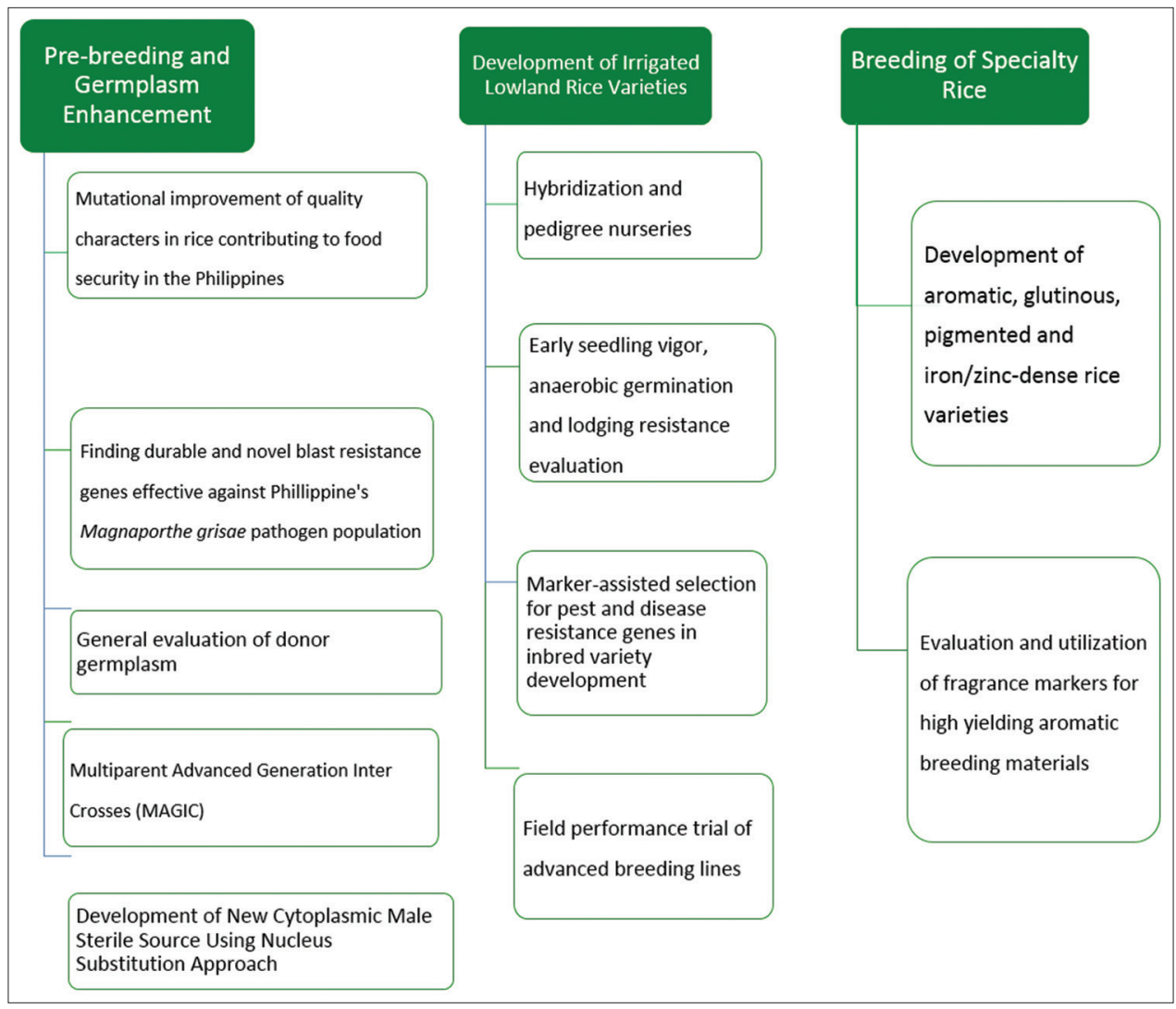

Figure 4. Core breeding projects and strategies implemented at the Philippine Rice Research Institute (PhilRice). 
Seventy-nine inbred and twelve hybrid promising lines (four were developed in collaboration with UPLB, one with PHILSCAT and one with Central Luzon State University) were entered in the pipeline of the National Cooperative Tests (NCT) and approved by the National Seed Industry Council (NSIC) as new varieties, from 1992 to 2019. Majority [32] of these varieties are suited to irrigated lowland; seventeen to rainfed lowland; eighteen to saline prone; three upland and two cool elevated areas. Most varieties had intermediate reaction to insect pest and diseases, except for tungro where under induced tests, these varieties were susceptible and for deadhearts and whiteheads stemborers, moderately susceptible. NSIC Rc216, NSIC RCl60 and NSIC Rc300 rice varieties bred by PhilRice were the top most preferred rice varieties of Filipino farmers in irrigated lowland fields nationwide, both for dry and wet season. NSIC Rc216 when transplanted has a maximum yield of $9.7 \mathrm{t} / \mathrm{h}$ a with a maturity of 112 days after sowing (DAS). It is moderately resistant to brown planthoppers (BPH) and green leafhoppers (GLH). NSIC Rcl60 has a maximum yield of $8.2 \mathrm{t} /$ ha of direct-wet-seeded and matures in 107 DAS. It has intermediate reaction to blast, bacterial leaf blight (BLB) and GLH, and resistant to stemborer. This variety is also known for its good eating quality because of its low amylose content. Transplanting NSIC Rc300 could yield as high as $10.4 \mathrm{t} / \mathrm{ha}$ and matures in 115 DAS. It is moderately resistant to both BPH and GLH, and has intermediate reaction to BLB. PhilRice has also developed one variety that is resistant to rice tungro virus, NSIC Rcl20 also known as Matatag 6 in 2003.

\section{Magsasaka at siyentipiko para sa pag-unlad ng agrikultura (MASIPAG)}

MASIPAG or the Farmer-Scientist Partnership for Agricultural Development was established in 1986. It aims to improve the quality of life of resource poor farmers through a farmerled sustainable agriculture approach. The network reaches farmer members in the three main regional zones of the Philippines: Luzon, Visayas and Mindanao. The rice breeding and agricultural innovations are led by farmers while decisionmaking structures are based on a bottom up approach. The approach builds on farmers' knowledge in active ways, not only working with traditional knowledge but incorporating farmers as fundamental to the farmer-scientist partnership. Involvement in farmer-led sustainable agriculture is seen to facilitate empowerment. The MASIPAG network emerged from the BIGAS (Bahanggunian ng mga Isyu higgil sa Bigas) or Conference on Rice Issues that was held in July 1985 to discuss problems associated with the high-input agricultural techniques and chemically-dependent, genetically uniform HYVs of rice associated with Green Revolution. Farmers who joined the conference donated the first 47 rice varieties of the first MASIPAG seed collection. MASIPAG was formally launched with the establishment of a three-hectare Back UP and Research Farm (BURF) in 1986 which became the model and core of the rice genetic conservation and improvement program.

Farmers and scientists worked closely together to produce the first MASIPAG lines and to create environmental-friendly cultural management practices. The first crop had 54 varieties consisting of 15 selectons and 39 new collections. In 2008, the three national backup farms, 10 regional community seed banks and 272 trial farms in 40 provinces hold more than 2000 local varieties and farmer-bred lines [10]. The MASIPAG approach is farmer-centered and bottom-up. Farming families are encouraged to learn and work together in groups. These groups, or people's organizations (POs) form the basis of the MASIPAG structure and are the level through which most work gets done, training is conducted and decisions are made. Both technological change (adoption of sustainable agriculture) and social change (increased knowledge, awareness, understanding and the ability to act privately or as a member or leader in the community) are prioritized. Combined, the two aspects lead to tangible ecological and economic benefits, ownership and control of resources, and social empowerment. Rice breeding in the MASIPAG networks has evolved beyond participatory plant breeding because farmers are now breeding their own rice, maintain germplasm in their own farms, select the materials by themselves, do cross pollination, make selections of segregating lines, evaluate their selections, and share developed varieties with another farmer. Many farmers got interested in breeding because of their feeling of reinforcement by other farmers, scientists and NGO workers. The tangible results of their breeding work were not only a solution to their farming problems, but also a source of pride when other farmers planted the rice that they bred [11]. In 2013, more than 2,000 rice varieties were collected and maintained. In response to adverse agroclimatic conditions brought about by climate change, MASIPAG has documented MASIPAG rice, farmer-bred rice and TRVs with particular adaptation: 12 flood tolerant varieties, 18 drought tolerant varieties, 20 saline (saltwater) tolerant varieties and 24 pests or diseases resistant varieties.

\section{Breeding Prospects}

Sufficient number of varieties have been developed and disseminated in the country for the past decades. The adoption of improved varieties brought dramatic increase in rice production few decades ago. Even though production continues to increase, however, cannot cope with the increase in demand. With the dwindling of land area devoted to rice production, increasing farm productivity through increasing farmer's yield is probably the best option. However, genetic gains in grain yield have been dismal and yield trend tends to plateau. Furthermore, rice production is constantly challenge with environmental constraints brought climate change, pest infestations involving old and new emerging pests, nutrient stresses, and others. The archipelagic nature of the country that consequently results to diverse rice production ecosystems calls for variety(ies) with either location-specific adaptability or wide adaptability. Breeders should develop varieties that have stable yield with multiple resistance to pest, early to medium maturing, and resilient to adverse conditions.

To effectively and efficiently address challenges in breeding, breeding institutions should embrace advances, and new technologies and tools that have been proven to be effective. IRRI, a leading authority in rice research and development, have been pioneering development and adoption of advance breeding 
strategies using cutting-edge technologies. Scientist and breeders at IRRI have proposed strategies that could increase rate of genetic gains in grain yield and other traits, and improve effectiveness and efficiency of breeding operations [12]. The propose changes include rapid generation advance, earlier multilocation trials, increased selection pressure for yield, intensify use of molecular breeding, and use of variety product profile [12]. Furthermore, it was suggested that breeding operations should be streamlined to make breeding like a "factory line" [12]. Essentially, local breeding institutions such as PhilRice and UPLB should adopt such technologies to successfully achieve breeding goals. However, government funding poses a major challenge. Policy-makers should consider allotting more budget for rice R\&D achieve significant impact in rice breeding.

Breeding for micronutrient-densed varieties through biofortification should also be intensify to address eminent problem on micronutrient deficiencies that are prevalent in the country. As of the moment, there are only two varieties available (NSIC R460, zinc-biofortifed and IR72, iron-biofortified) both developed by IRRI. There is an existing large genetic variability in rice germplasm especially for Zn micronutrient concentration that can be exploited to develop promising lines through biofortification [13]. IRRI has been working intensively in past years developing promising lines that already in the pipeline for release. PhilRice has started collaborating with IRRI on this matter but is lagging behind. It would be appropriate for PhilRice and UPLB to engage in this breeding program.

\section{REFERENCES}

1. Mariano M, Villano R, Fleming E. Factors influencing farmers' adoption of modern rice technologies and good management practices in the Philippines. Agric Syst. 2012 Jul 1;110.

2. Launio CC, Redondo GO, Beltran JC, Morroka Y. Adoption and
Spatial Diversity of Later Generation of Modern Rice Varieties in the Philippines. Agron J. 2008;100(5):1380-9.

3. Mackill DJ, Khush GS. IR64 : a high-quality and high-yielding mega variety. 2018.

4. Khush G. Green revolution: preparing for the $21^{\text {st }}$ century. Genome [Internet]. 1999;42(4):646-55. Available from: https://www.ncbi.nlm. nih.gov/pubmed/10464789.

5. Khush GS, Virk PS. IR varieties and their impact [Internet]. $1^{\text {st }}$ ed. Los Banos, Laguna, Philippines: International Rice Research Institute; 2005. Available from: https://books.google.com $\mathrm{ph} / \mathrm{books}$ ? hl=en\&lr=\&id=7ErTt58v5CoC\&oi=fnd\&pg =PR4\&o ts $=$ GLmSa9DsYY\&sig =i7MP2rDhOqs1aKLVIfIOz6tyM5o\&red ir_esc $=\mathrm{y} \# \mathrm{v}=$ onepage $q q \& \mathrm{f}=$ false

6. IRRI. Transforming lives through the global rice sector. Strategic Plan 2017-2025 [Internet]. 2019. Available from: http://books.irri.org/ strategic-plan-2017-2025.pdf

7. IRRI. High-yielding Rice [Internet]. Los Banos, Laguna, Philippines; 2019. Available from: https://www.irri.org/high-yielding-rice

8. IRRI. Research Platform: Research Breeding [Internet]. 2019 Available from: https://www.irri.org/research-platform/rice-breeding

9. National Seed Industry Council. Quirino Avenue, Malate, Manila, Philippines.

10. Bachmann L, Cruzada E, Writh S. Food Security and Farmer Empowerment: A study of the impacts of farmer-lead sustainable agriculture in the Philippines [Internet]. Los Banos, Laguna, Philippines; 2009. 24-29 p. Available from: https://www. researchgate.net/publication/293817680 Food security and farmer_empowerment_a_study_of_the_impacts_of_farmer-led_ sustainable_agriculture_in_the_Philippines/stats

11. Medina CP. Rice: Crop Breeding Using farmer-Led Participatory Plant Breeding. In: Lammerts van Beuren ET, Myers JR, editors. Organic Crop Breeding [Internet]. Wiley Online Library; 2011. Available from: https://onlinelibrary.wiley.com/doi/10.1002/9781119945932.ch11

12. Collard BCY, Gregorio GB, Thompson MG, Islam M, Vergara GV, Laborte AG, et al. Transforming Rice Breeding: Redesigning the Irrigated Breeding Pipeline at International Rice Research Institute (IRRI). Crop Breeding, Genet Genomics [Internet]. 2019;1:e190008. Available from: https://doi.org/10.20900/cbgg20190008

13. Swamy BPM, Rahman MA, Inabangan-Asilo MA, Amparado A, Manito C, Chadha-Mohanty P, et al. Advances in breeding for high grain Zinc in Rice. Rice. 2016;9(1). 